\title{
Soroepidemiologia da toxoplasmose em caprinos e ovinos de três municípios do Estado do Rio de Janeiro ${ }^{1}$
}

\author{
Daniela M. Luciano ${ }^{2 *}$, Rodrigo C. Menezes ${ }^{3}$, Luiz C. Ferreira ${ }^{3}$, José L. Nicolau ${ }^{2}$, \\ Leandro B. das Neves ${ }^{2}$, Raquel M. Luciano ${ }^{2}$, Magyda A.A. Dahroug ${ }^{2}$ \\ e Maria Regina R. Amendoeira ${ }^{2}$
}

\begin{abstract}
Luciano D.M., Menezes R.C., Ferreira L.C., Nicolau J.L., Neves L.B., Luciano R.M., Dahroug M.A.A. \& Amendoeira M.R.R. 2011. [Seroepidemiology of toxoplasmosis in goats and sheep from three counties of Rio de Janeiro state, Brazil.] Soroepidemiologia da toxoplasmose em caprinos e ovinos de três municípios do Estado do Rio de Janeiro. Pesquisa Veterinária Brasileira 31(7):569-574. Laboratório de Toxoplasmose, Instituto Oswaldo Cruz, Fiocruz, Av. Brasil 4365, Rio de Janeiro, RJ 21040-360, Brazil. E-mail: amendoei@ioc.fiocruz.br

Toxoplasmosis is a worldwide zoonosis caused by Toxoplasma gondii. Epidemiological surveys of T. gondii infection among livestock have great economical importance since this infection may cause abortion, growth retardation and neonatal mortality, with significant losses to breeders. In regard of public health, human infection can be acquired by ingestion of meat or milk in natura from infected livestock. The aim of this study was to assess the toxoplasmosis seroprevalence by indirect immunofluorescence antibody test (IFAT) in goats and sheep, in three counties of Rio de Janeiro state, from 10 different farms. The seroprevalences of anti-T.gondii IgG antibodies were $29.12 \%$ (60/206) in goats and 38.05\% $(137 / 360)$ in sheep, with titers ranging from 64 to 256, suggesting chronic infection. Association of each of the following epidemiological factors: female gender, adult age, extensive management system, grazing pasture and drinking lake water with seropositivity was observed only in sheep $(\mathrm{p} \leq 0.05)$. Improvement in breeding conditions may reduce the sources of infection in herds.
\end{abstract}

INDEX TERMS: Toxoplasma gondii, goats, sheep, seroepidemiology.

RESUMO.- A toxoplasmose é uma zoonose de ampla distribuição mundial, causada pelo Toxoplasma gondii. 0 estudo da prevalência desta infecção em animais produtores de carne e leite é de interesse à saúde pública, devido ao fato desses produtos oriundos de animais infectados serem importantes vias de transmissão para o homem, quando consumidos in natura. Além disso, há o aspecto econômico, uma vez que pode causar aborto, retardo no crescimento e animais debilitados, levando prejuízos ao pecuarista. Este trabalho objetivou estimar a soroprevalência da infecção por T. gondii, por meio da reação de imunofluorescência indireta (RIFI) em caprinos

\footnotetext{
${ }^{1}$ Recebido em 22 de dezembro de 2010. Aceito para publicação em 5 de março de 2011

${ }^{2}$ Laboratório de Toxoplasmose, Instituto Oswaldo Cruz (IOC), Fiocruz, Av. Brasil 4365, Manguinhos, Rio de Janeiro, RJ 21040-900, Brasil. *Autor para correspondência: amendoei@ioc.fiocruz.br

${ }^{3}$ Serviço de Zoonoses, Instituto de Pesquisa Clínica Evandro Chagas (IPEC), Fiocruz, Av. Brasil 4365, Manguinhos, Rio de Janeiro, RJ 21040360, Brasil.
}

e ovinos de três municípios do estado do Rio de Janeiro, provenientes de 10 propriedades. A prevalência de anticorpos IgG anti-T.gondii foi de 29,12\% (60/206) nos caprinos e de $38,05 \%(137 / 360)$ nos ovinos, sendo observada nessa última espécie associação $(\mathrm{p} \leq 0,05)$ entre sexo (fêmeas), idade adulta, sistema de criação extensivo, dieta de pastagem e água de beber de açude com a soropositividade. Os títulos variaram de 64 a 256, podendo ser sugestivos de infecção crônica. Melhorias nas técnicas de criação podem reduzir as fontes de infecção por T. gondii nos rebanhos.

TERMOS DE INDEXAÇÃO: Toxoplasma gondii, ovinos, caprinos, soroepidemiologia.

\section{INTRODUÇÃO}

A toxoplasmose é uma zoonose de distribuição mundial que acomete o homem e outros animais de sangue quente, sendo causada pelo protozoário Toxoplasma gondii, única espécie existente no gênero (Amendoeira et al. 1999). Os gatos são a chave da transmissão da doença, pois juntamente com os de- 
mais felídeos são os únicos hospedeiros que eliminam os oocistos pelas fezes (Dubey \& Jones 2008), contaminando o ambiente e propagando a infecção (Amendoeira et al. 1995).

Segundo Dubey (1987) T. gondii é mais patogênico para os caprinos quando comparado aos demais animais de produção, causando morte fetal, mumificação, abortos ou nascimento de animais debilitados, ocasionando perdas econômicas. Para os ovinos, o agente causa abortamentos e problemas reprodutivos (Meireles et al. 2003), como esterilidade e morte neonatal (Dubey \& Jones 2008).

Caprinos e ovinos infectados por T. gondii representam uma fonte de infecção importante para os seres humanos, devido à ingestão de leite in natura e carne crua ou mal cozida contaminados destes animais (Millar et al. 2008).

A infecção por T. gondii em caprinos e ovinos encontra-se amplamente distribuída pelo mundo, apresentando soroprevalências variando entre 3,2\% e 30\% para caprinos (Dubey 1985, Garcia-Vasquez et al. 1993, Samad et al. 1993, HashemiFesharki 1996, Masala et al. 2003, Sharif et al. 2007, Zia-Ali et al. 2007) e entre 7\% e 38,5\% para ovinos (Dubey 1985, Samad et al. 1993, Hashemi- Fesharki 1996, Freyre et al 1997, Skjerve et al. 1998, Gorman et al. 1999, Masala et al. 2003, Sawadogo et al. 2005, Fusco et al. 2007, Zia-Ali et al. 2007, Sharma et al. 2008). No Brasil, em diversos estados, estudos demonstram inquéritos que apresentam soroprevalências da infecção em caprinos entre 5,9\% e 46,0\% (Mainardi et al. 2000, Figueiredo et al. 2001, Meireles et al. 2003, Silva et al. 2003, Cavalcante et al. 2007, Carneiro et al. 2009) e em ovinos entre 7,7\% e 54,6\% (Garcia et al. 1999, Gondim et al.1999, Silva \& Lagoni 2001, Meireles et al. 2003, Ogawa et al. 2003, Romanelli et al. 2007, Soares et al. 2009, Lopes et al. 2010).

De acordo com a literatura, a prevalência da infecção por $T$. gondii em ovinos é relativamente maior do que em caprinos, podendo ser explicada pela susceptibilidade das espécies. Além disso, as variações na maneira de pastagem podem explicar a diferença no índice de infecções. Os ovinos pastam mais rasteiramente que os caprinos ao preferirem folhas mais novas e gramíneas de porte mais baixo, principalmente peridomiciliar, o que favorece a possível ingestão de oocistos. Entretanto, os caprinos consomem o topo das gramíneas e partes mais altas de arbustos (Ogawa et al. 2003, Sharif et al. 2007).

Este trabalho teve como objetivo estudar a soroprevalência da infecção por T. gondii, utilizando a reação de imunofluorescência indireta (RIFI), em caprinos e ovinos de três municípios distintos do estado do Rio de Janeiro.

\section{MATERIAL E MÉTODOS}

Foi realizado um estudo descritivo transversal em 566 animais oriundos de 10 propriedades rurais da região de baixadas litorâneas, dos municípios de Casemiro de Abreu(22 ${ }^{\circ} 28^{\prime} 50^{\prime \prime} \mathrm{S}, 42^{\circ} 12^{\prime} 15^{\prime \prime}$ 0), Silva Jardim ( $22^{\circ} 42^{\prime} 28^{\prime \prime}$ S, $42^{\circ} 37^{\prime} 33^{\prime \prime} 0$ ) e Maricá (22055'10" S, 42 $49^{\prime} 07^{\prime \prime} 0$ ), no estado do Rio de Janeiro.

Os caprinos pertenciam a duas propriedades rurais produtoras de leite, no município de Maricá, uma com sistema de criação semi-intensiva e a outra extensiva. $\mathrm{O}$ alimento e a água oferecidos aos animais variaram conforme o tipo de criação. A criação extensiva fornecia somente pastagem e água de nascente e a criação semiintensiva, pastagens e ração, com acréscimo de sal mineral e água de açude.

Os ovinos para abate eram procedentes de oito propriedades sendo duas com sistema de criação extensiva, uma intensiva e cinco semi-intensivas. A alimentação destes animais era basicamente composta por pastagens nas criações extensivas; ração na criação intensiva e pastagens e ração, com suplementação à base de sal mineral nas criações semi-intensivas. Quanto à água de consumo, em quatro propriedades (três de criação semi-intensiva e uma extensiva) havia acesso dos animais às nascentes; em três (uma extensiva e duas semiintensivas) os açudes eram a fonte hídrica destes e na propriedade de criação intensiva era fornecida água de poço artesiano.

A determinação do número de amostras, assim como a avaliação dos resultados foram obtidos por meio do programa Epi-Info versão 3.5.1 (CDC 2008). 0 cálculo amostral foi baseado na população total de animais por espécie, considerando a soma do rebanho dos três municípios estudados, de acordo com dados obtidos pelo censo pecuário do IBGE de 2008. No caso dos caprinos, foi considerada apenas a população total do município de Maricá. Adotou-se como referência uma prevalência esperada de $50 \%$, intervalo de confiança de 95\% e erro absoluto de 0,05.

As coletas foram realizadas após assinatura do termo de consentimento livre e esclarecido pelos proprietários. Em seguida, os mesmos responderam a um questionário epidemiológico, que contemplava dados dos animais como idade, sexo, espécie, raça, tipo de criação, procedência, presença de gatos, entre outros. Dentre os animais, foram coletadas 206 amostras de sangue de caprinos e 360 de ovinos, obtidas através de venocentese jugular (5-10mL) em tubos de ensaios estéreis sem anticoagulante. As amostras foram enviadas ao Laboratório de Toxoplasmose do IOC/Fiocruz, em isopor com gelo e centrifugadas. Os soros foram armazenados a $-20^{\circ} \mathrm{C}$.

Todos os caprinos eram fêmeas adultas com idade entre um e três anos, no entanto, no rebanho ovino, 315 (87,5\%) animais eram adultos, com idade entre um e quatro anos e $45(12,5 \%)$ animais jovens, com idade entre seis meses a um ano, 64 (17,8\%) machos e $296(82,2 \%)$ fêmeas. A maioria deles não apresentava raça definida, sendo resultado de cruzamentos inter-raciais.

Os soros foram analisados para detecção de anticorpos anti-T. gondii da classe IgG, por meio da RIFI de acordo com Camargo (1964). Inicialmente foi realizada uma triagem das amostras, na qual foram feitas diluições iniciais de 1:64 e 1:256. As amostras reativas tiveram diluições estendidas ao quádruplo, até 1:4096 para a leitura da RIFI, sendo consideradas positivas aquelas com titulação $\geq 64$ em caprinos (Figueiredo et al. 2001) e em ovinos (Garcia et al. 1999). A leitura das lâminas foi realizada em microscópio Y-FL de epi-fluorescência (Nikon), com lâmpada de mercúrio, filtro ND16, com objetiva de 40 vezes e ocular de 10 vezes, considerando-se positiva a maior diluição do soro em que havia fluorescência completa na borda, de pelo menos 50\% dos taquizoítas.

Para verificar a associação entre duas variáveis categóricas, foi realizado o Teste qui-quadrado de Pearson. No caso da avaliação de tabelas formadas por duas linhas e duas colunas foi empregada uma correção, denominada Yates. Entretanto, no caso de baixos valores nas células da tabela $(\mathrm{n}<5)$ foi empregado um teste alternativo não paramétrico, denominado Teste Exato de Fisher. Os resultados sorológicos associados às variáveis foram considerados estatisticamente significativos quando $\mathrm{p} \leq 0,05$. Na avaliação do impacto entre as variáveis, foram descritos os valores das razões de chances (OR) com seus respectivos intervalos de confiança (IC) de 95\%.

Este trabalho foi aprovado pela Comissão de Ética no Uso de Animais (CEUA), sob protocolo P-520/08 e licença L-006/09 pelo CEUA/Fiocruz.

\section{RESULTADOS}

Obteve-se uma prevalência de anticorpos IgG anti-Toxoplasma gondii de $29,12 \%$ nos caprinos e de $38,05 \%$ nos ovinos (Quadro 1) . 
Quadro 1. Prevalência de anticorpos IgG anti-T. gondii pela RIFI, em soros de caprinos e ovinos com os respectivos títulos, oriundos de três municípios do estado do Rio de Janeiro

\begin{tabular}{|c|c|c|c|c|}
\hline \multicolumn{2}{|c|}{$\operatorname{Amostra}(\mathrm{N})^{\mathrm{a}}$} & \multicolumn{2}{|c|}{ Reagentes } & \multirow{3}{*}{$\begin{array}{c}\text { Intervalo de } \\
\text { confiança (95\%) } \\
\mathbf{2 3 , 0 2 \%}-\mathbf{3 5 , 8 5 \%}\end{array}$} \\
\hline & & $\mathrm{N}$ & $\%$ & \\
\hline Caprinos & \multirow[t]{3}{*}{206} & 60 & 29,12 & \\
\hline Título 64 & & 31 & 51,70 & \\
\hline Título 256 & & 29 & 48,30 & \\
\hline Ovinos & \multirow[t]{3}{*}{360} & 137 & 38,05 & $33,02 \%-43,29 \%$ \\
\hline Título 64 & & 74 & 54,00 & \\
\hline Título 256 & & 63 & 46,00 & \\
\hline
\end{tabular}

a Número de amostras examinadas.

Quadro 2. Frequência absoluta (número de reagentes) e relativa (\%) dos caprinos submetidos à RIFI, segundo os possíveis fatores de risco associados à infecção por T. gondii, obtidos a partir de dados coletados em questionário epidemiológico em duas propriedades rurais

\begin{tabular}{lccc}
\hline \multicolumn{1}{c}{ Variáveis ambientais } & \multicolumn{2}{c}{ Caprinos } \\
& & \multicolumn{2}{c}{$(\mathrm{N}=206)^{\mathrm{a}}$} \\
\cline { 3 - 4 } & & Reagentes & $\%$ \\
\hline Sistema de criação & Extensiva (5) & 1 & 20,00 \\
pFisher=1 & Intensiva (0) & 0 & 0,0 \\
Dieta & Semi-intensiva (201) & 59 & 29,35 \\
pFisher=1 & Pastagem (5) & 1 & 20,00 \\
& Ração (0) & 0 & 0,0 \\
Água de beber & Ração e pastagem (201) & 59 & 29,35 \\
pFisher=1 & Tratada (0) & 0 & 0,0 \\
& Poço artesiano (0) & 0 & 0,0 \\
& Açude (201) & 59 & 29,35 \\
Presença de gatos & Cisterna (0) & 0 & 0,0 \\
& Nascente (5) & 1 & 20,00 \\
& Sim (206) & 60 & 29,12 \\
& Não (0) & 0 & 0,0
\end{tabular}

$\bar{a}$ Número de amostras examinadas.

Em caprinos, o título 64 foi observado em $51,7 \%$ das amostras enquanto o título 256 foi detectado em 48,3\% (Quadro 1). Todos os animais analisados eram fêmeas adultas acima de um ano de idade. Problemas reprodutivos (abortos, natimortos ou recém-nascidos debilitados) foram observados na propriedade com sistema de criação semi-intensivo. A presença de gatos com acesso as residências, pastos, currais, hortas e depósitos de rações foram relatadas em todas as propriedades, por isso a variável "presença de gatos", não sofreu tratamento estatístico. Não houve relato de casos de animais com sintomatologia nervosa ou ocular nos últimos 12 meses. As variáveis sistema de criação (pFisher=1), dieta ( $p F i$ isher=1) e água de beber ( $p$ Fisher=1) não apresentaram associação estatisticamente significativa em relação à infecção por T. gondii (pFisher=1) (Quadro 2).

Nos ovinos, quanto ao sexo, $40,88 \%$ das fêmeas e $25 \%$ dos machos eram sororeagentes. Quanto à idade, houve soropositividade em $40,95 \%$ dos adultos e em $17,77 \%$ dos jovens. 0 título 64 ocorreu em $54 \%$ dos sororeagentes e os outros $46 \%$ apresentaram título 256 (Quadro 1). Houve diferenças estatísticas significativas entre a soropositividade dos ovinos, quando comparados ao sexo $(\mathrm{x} 2=4,97$; pYates $=0,02)$ com maior ocorrência nas fêmeas e quando comparados a idade $(x 2=8,01$; pYates $=0,005)$, com maior ocorrência nos
Quadro 3. Frequência absoluta (número de reagentes) e relativa (\%) dos ovinos submetidos à RIFI, segundo os possíveis fatores de risco associados à infecção por T. gondii, obtidos a partir de dados coletados em questionário epidemiológico em oito propriedades rurais

\begin{tabular}{|c|c|c|c|}
\hline \multicolumn{2}{|c|}{ Variáveis ambientais } & \multicolumn{2}{|c|}{$\begin{array}{l}\text { Ovinos } \\
(\mathrm{N}=360)^{\mathrm{a}}\end{array}$} \\
\hline & & Reagentes & $\%$ \\
\hline \multirow{3}{*}{$\begin{array}{l}\text { Sistema de criação } \\
(x 2=6,71 ; \text { pPearson }=0,03)\end{array}$} & Extensiva(35) & 19 & 54,28 \\
\hline & Intensiva(65) & 29 & 44,61 \\
\hline & Semi-intensiva(260) & 89 & 34,23 \\
\hline \multirow{3}{*}{$\begin{array}{l}\text { Dieta } \\
(x 2=6,71 ; \text { pPearson }=0,03)\end{array}$} & Pastagem(35) & 19 & 54,28 \\
\hline & Ração(65) & 29 & 44,61 \\
\hline & Ração e pastagem(260) & 89 & 34,23 \\
\hline \multirow{5}{*}{$\begin{array}{l}\text { Água de beber } \\
(\mathrm{x} 2=16,18 ; \text { pPearson }<0,001)\end{array}$} & Tratada $(0)$ & 0 & 0,0 \\
\hline & Poço artesiano(65) & 29 & 44,61 \\
\hline & Açude(167) & 77 & 46,11 \\
\hline & Cisterna $(0)$ & 0 & 0,0 \\
\hline & Nascente(128) & 31 & 24,22 \\
\hline \multirow{2}{*}{$\begin{array}{l}\text { Presença de gatos } \\
(\mathrm{x} 2=0,18 ; \text { pYates }=0,67)\end{array}$} & $\operatorname{Sim}(284)$ & 106 & 37,32 \\
\hline & Não(76) & 31 & 40,79 \\
\hline
\end{tabular}

a Número de amostras examinadas.

adultos. Observou-se que as fêmeas possuem 1,07 vezes mais chances de serem reagentes do que os machos $(\mathrm{OR}=2,07$; IC[95\%] $=1,94-4,10)$ e que os adultos possuem 2,20 vezes mais chances de serem reagentes do que os jovens $(\mathrm{OR}=3,20$; IC $[95 \%]=1,41-8,22)$.

Houve também associação estatística significativa dos ovinos sororeagentes em relação às variáveis: sistema de criação, alimentação e água de beber (Quadro 3). Quanto ao sistema de criação extensivo, com alimentação de pastagem, observou-se que estes animais possuíam 1,27 vezes mais chances de serem reagentes do que os animais criados semiintensivamente, com a dieta de pastagem e ração, $(\mathrm{OR}=2,27$; IC[95\%]=1,05-4,98], não havendo diferença estatisticamente significativa quando comparados os sistemas intensivo (somente ração) e semi-intensivo (OR=1,54; IC[95\%]=0,85$2,78)$. Os que bebiam água de açude tinham 1,67 vezes mais chances de serem reagentes dos que ingeriam água de nascente $(\mathrm{OR}=2,67$; IC[95\%]=1,57-4,60). Já os que consumiam água de poço tinham 1,51 vezes mais chances de serem reagentes dos que bebiam água de nascente $(\mathrm{OR}=2,51$; IC $[95 \%]=1,27-4,98)$. Não foi observada diferença significante em relação à soropositividade e a presença de gatos $(\mathrm{x} 2=0,18$; pYates $=0,67)$.

\section{DISCUSSÃO}

Na espécie caprina, valores similares de prevalência de infecção por Toxoplasma gondii foram observados no Brasil por Figliuolo et al. (2004b) em São Paulo (28,70\%), Gondim et al. (1999) na Bahia $(28,93 \%)$ e Neto et al. (2008) no Rio Grande do Norte $(30,60 \%)$. Dados semelhantes também foram observados em outros países, relatando 27,0\% em Gana (Van Der Puije et al. 2000) e 30,0\% no Irã (Sharif et al. 2007).

No presente estudo, todos os animais eram adultos acima de um ano de idade. Em outros estudos, também foram encontrados associação positiva entre a presença de anticorpos e a idade adulta de caprinos (Figueiredo et al. 2001, Figliuolo et al. 2004b, Carneiro et al. 2009). 
A caprinocultura no Brasil é mais voltada para a produção leiteira, havendo maior proporção de fêmeas em relação aos animais machos, o que pode influenciar a elevação das taxas de infecção em fêmeas (Silva et al. 2003). Além disso, estas atingem idade mais avançada que os animais de corte. Neste contexto, só foram avaliadas fêmeas.

Os títulos detectados no presente estudo foram de 64 e 256. Estes valores também foram observados por HashemiFesharki (1996). De acordo com Garcia et al. (1999), baixos títulos de anticorpos são sugestivos de infecções crônicas, com presença de cistos teciduais, sendo esses animais possíveis portadores desta forma evolutiva do T. gondii, o que o tornaria uma fonte de infecção do parasito.

Em relação ao sistema de criação, observou-se maior percentual de sororeagentes para os caprinos no sistema semiintensivo (29,35\%), corroborando com os estudos de Meireles et al. (2003) e Neto et al. (2008). Embora houvesse maior número de animais sororeagentes que consumiam água de açude em relação aos que bebiam água de nascente, não foi verificada diferença estatisticamente significativa.

A presença de felinos em todas as propriedades com livre acesso às instalações foi um achado importante, o que poderia explicar a elevada taxa de infecção encontrada. Apesar da análise estatística não ter revelado associação significativa entre a presença de gatos e a ocorrência de caprinos soropositivos, Neto et al. (2008) encontraram esta associação e indicaram que a presença destes animais e o contato próximo com os mesmos são importantes na cadeia epidemiológica da infecção, uma vez que os felídeos são os únicos hospedeiros que excretam oocistos no meio ambiente pelas fezes, podendo contaminar a pastagem, a ração e a água de beber dos animais. A falta de associação entre a presença de gatos e soropositividade dos caprinos pode ser devido ao pequeno número de propriedades estudadas.

Nos ovinos, verificou-se uma alta prevalência. Este resultado está em concordância com as taxas observadas no Brasil, como 34,70\% em São Paulo (Figliuolo et al. 2004a) e $35,30 \%$ em Pernambuco (Silva et al. 2003). Valores similares foram observados em outros países, com taxas de 33,20\% em Gana (Van Der Puije et al. 2000), 35\% no Irã (Sharif et al. 2007), 37,74\% na França (Dumetre et al. 2006) e 38,50\% no Uruguai (Freyre et al. 1997).

As titulações predominantemente encontradas foram semelhantes aos relatados por Hashemi-Fesharki (1996) e, assim como nos caprinos, podem estar relacionados a infecções crônicas (Garcia et al. 1999, Ogawa et al. 2003).

Quanto à faixa etária, houve diferença estatística significativa $(p \leq 0,05)$, com maior porcentagem de sororeagentes em animais com idade acima de um ano $(40,95 \%)$. Estes resultados estão de acordo com os obtidos por Garcia et al. (1999), Van der Puije et al. (2000), Ogawa et al. (2003), Figliuolo et al. (2004a) e Romanelli et al. (2007), sugerindo que a soropositividade aumenta com a idade e que os animais adultos estiveram por mais tempo em contato com as possíveis vias de transmissão do T. gondii, resultando em maior chance de se infectarem. A soropositividade dos cordeiros (animais abaixo de um ano de idade) não deve estar relacionada à transferência de anticorpos maternos via colostro, pois isto pode ocorrer dentro de três meses após o nascimento (Dumetre et al. 2006) e os animais do estudo tinham idade a partir de cinco meses.

Em relação ao sexo mostrou-se diferença estatisticamente significativa $(\mathrm{p} \leq 0,05)$, com maior soropositividade nas fêmeas $(40,88 \%)$ do que nos machos (25\%), tal fato também foi relatado por Van der Puije et al. (2000).

No sistema de criação, observou-se maior percentual de sororeagentes para os ovinos de criação extensiva $(54,28 \%)$ com diferença estatisticamente significativa $(p \leq 0,05)$, corroborando os achados de Meireles et al. (2003). Possivelmente, esta infecção se deve ao fato de que os animais criados em manejo extensivo estarem mais expostos à pastagem e a água contaminadas por oocistos de T. gondii. Entretanto, os animais criados em sistema semi-intensivo e intensivo estariam menos expostos a estes fatores (Meireles et al. 2003).

Analisando-se a água de beber, a maior taxa de infecção nos ovinos foi obtida pelo consumo de água de açude $(46,11 \%)$, seguida de água de poço $(44,61 \%)$ e água de nascente $(24,22 \%)$, havendo diferença estatisticamente significativa entre estas fontes hídricas ( $p<0,001)$. Romanelli et al. (2007) observaram resultados semelhantes, também com diferença significativa entre as fontes de água e positividade na mesma ordem de consumo. Assim como os caprinos, o consumo de água de açude, seguida de água de poço, apresentou maior número de sororeagentes do que o de água de nascente, talvez por se tratar de água corrente, com menos chances de contaminação com oocistos infectantes.

A presença de felinos em $75 \%$ das propriedades do presente estudo, com livre acesso às instalações, têm fundamental importância na epidemiologia do T. gondii, já que os oocistos eliminados nas fezes dos gatos podem, dependendo das condições ambientais, perdurarem infectantes por vários meses até anos no meio ambiente (Ogawa et al. 2003). A análise estatística não revelou associação significativa nesta variável, ao contrário do constatado por Skjerve et al. (1998) e Romanelli et al. (2007) que encontraram associação. Skjerve et al. (1998) destaca que a presença do gato por si só não é considerada fator de risco, pois especialmente os gatos jovens são os principais responsáveis pela liberação de oocistos.

Todas as propriedades de ovinos e caprinos situavam-se em região rural e a maioria delas era vizinha a reservas florestais de Mata Atlântica, com relatos dos proprietários sobre a presença esporádica de animais silvestres nestas áreas, incluindo os felinos silvestres. Silva et al. (2002) descreveram a presença de anticorpos anti-T. gondii em várias espécies de felídeos Neotropicais do Brasil. Ainda que o gato doméstico seja o único hospedeiro definitivo urbano, outros felídeos também são capazes de manter o ciclo epidemiológico em áreas não urbanizadas (Bonametti et al. 1997). Dubey \& Jones (2008) afirmam que a prevalência da infecção por T. gondii é mais alta nos felinos selvagens do que nos felinos domésticos.

$\mathrm{Na}$ ausência de gatos domésticos, tal como ocorre em regiões do interior do país, Sobral et al. (2005) verificaram que a alta prevalência de anticorpos $(55,6 \%$ a $80,4 \%)$ em populações rurais e indígenas pode provavelmente ser atribuída aos felinos silvestres, que são capazes de eliminar oocistos de T. gondii pelas fezes, nas proximidades das aldeias e cole- 
ções de água, contaminando o solo, e conseqüentemente, a água, os insetos e fungos consumidos pelos índios. 0 mesmo pode ter ocorrido nas propriedades estudadas, onde a presença de reserva florestal no entorno levavam tais animais a terem acesso às pastagens, contribuindo para aumentar o número de fontes de infecção.

As diferenças da frequência da infecção entre as regiões se devem, principalmente, ao tipo de teste sorológico utilizado, à localidade e a idade dos animais estudados (Mainardi et al. 2000, Silva et al. 2003).

Comparando-se a prevalência das diferentes espécies deste estudo, os resultados observados estão compatíveis com os obtidos por outros autores (Hashemi-Fesharki et al. 1996, Meireles et al. 2003, Sharif et al. 2007). Fatores como a susceptibilidade, o manejo das criações e as características de alimentação individuais de cada espécie podem ter influenciado nestes resultados.

\section{CONCLUSÕES}

A prevalência da infecção por Toxoplasma gondii foi de $29,12 \%$ nos caprinos e de $38,05 \%$ nos ovinos, ambos com baixos títulos de anticorpos, que podem ser sugestivos de infecções crônicas.

Esses valores de prevalência elevados destacam a importância destes animais como vias de transmissão ao homem, através da ingestão de seus derivados in natura.

Os ovinos apresentaram associação positiva $(p \leq 0,05)$ em relação ao sexo feminino e em relação à idade acima de um ano.

Na avaliação da influência das variáveis ambientais como fatores de risco para a infecção nos animais, somente os ovinos apresentaram associação positiva $(\mathrm{p} \leq 0,05)$ em relação ao sistema de criação extensiva, dieta à base de pastagem e consumo de água de açude.

Melhorias nas técnicas de criação podem reduzir as vias de transmissão por T. gondii nos rebanhos.

Agradecimentos.- Ao Prof. Dr. Hélio Langoni (Unesp, FMVZ Campus Botucatu) e à Drạ. Eliana Villalobos (Instituto Biológico, SP) pelos soros controles positivos e negativos para a RIFI de caprinos e ovinos, às Prof. Dr ${ }^{a}$. Carla Tavares Andrade e Drª‥ Raquel Vasconcellos (IPEC/Fiocruz), pelas análises estatísticas e ao Prof. Dr. Expedito Barros Coelho (Unigranrio) pelas coletas de material biológico.

\section{REFERÊNCIAS}

Amendoeira M.R.R. 1995. Mecanismos de transmissão da toxoplasmose. Anais da Academia Nacional de Medicina 155(4):224-225.

Amendoeira M.R.R., Costa T. \& Spalding S.M. 1999. Toxoplasma gondii Nicolle e Manceaux, 1909 (Apicomplexa: Sarcocystidae) e a Toxoplasmose. Revta Souza Marques 1(1):15-35.

Bonametti A.M., Passos J.N., Silva E.M.K. \& Bortoliero A.L. 1997. Surto de toxoplasmose aguda transmitida através da ingestão de carne crua de gado ovino. Revta Soc. Bras. Med. Trop. 30(1):21-25.

Camargo M.E. 1964. Improved technique of indirect immunofluorescence for serological diagnosis of toxoplasmosis. Revta Inst. Med. Trop. São Paulo. 6:117-118.

Carneiro A.C.A.V., Carneiro M., Gouveia A.M.G., Guimarães A.S., Marques A.P.R., Vilas-Boas L.S. \& Vitor R.W.A. 2009. Seroprevalence and risk factors of caprine toxoplasmosis in Minas Gerais, Brazil. Vet. Parasitol. 160:225229.

Cavalcante A.C.R., Ferreira A.M., Melo M.N., Fux B., Brandão G.P. \& Vitor
R.W.A. 2007. Virulence and molecular characterization of Toxoplasma gondii isolated from goats in Ceará, Brazil. Small Rumin. Res. 69:79-82.

CDC 2008. Epi Info. [acesso em 20 set. 2008]. Disponível em <http:// www.cdc.gov/epiinfo/ei2008.htm>

Dubey J.P. 1985. Serologic prevalence of toxoplasmosis in cattle, sheep, goats, pigs, bison and elk in Montana. J. Am. Vet. Med. Assoc. 186(9):969-970.

Dubey J.P. 1987. Toxoplasmosis in goats. Agri-Practice 3(8):43-52.

Dubey J.P. \& Jones J.L. 2008. Toxoplasma gondii infection in humans and animals in the United States. Int. J. Parasitol. 38:1257-1278.

Dumetre A., Ajzemberg D., Rozette L., Mercie A \& Dardé M. 2006. Toxoplasma gondii infection in sheep from Haute-Vienne, France: Seroprevalence and isolate genotyping by microsatellite analysis. Vet. Parasitol. 142: 376-379.

Figliuolo L.P.C., Kasai N., Ragozo A.M.A., Paula V.S.O., Dias R., Souza S.L.P. \& Gennari S.M. 2004a. Prevalence of anti-Toxoplasma gondii and anti-Neospora caninum antibodies in sheep from São Paulo State, Brazil. Vet. Parasitol. 123(3):161-166.

Figliuolo L.P.C., Rodrigues A.A.R., Viana R.B., Aguiar D.M., Kasai N. \& Gennari S.M. 2004b. Prevalence of anti-Toxoplasma gondii and anti-Neospora caninum antibodies in goat from São Paulo State, Brazil. Small Rumin. Res. 55:29-32.

Figueiredo J.F., Silva D.A.O., Cabral D.D. \& Mineo J.R. 2001. Seroprevalence of Toxoplasma gondii infection in goats by the Indirect Haemagglutination, Immunofluorescence and Immunoenzymatic Tests in the Region of Uberlândia, Brazil. Mem. Inst. Oswaldo Cruz. 96(5):687-692.

Freyre A., Bonino J., Falcon J., Castells D., Correa O. \& Casaretto A. 1997. The incidence and economic significance of ovine toxoplasmosis in Uruguay. Vet. Parasitol. 73:13-15.

Fusco G., Rinaldi L., Guarino A., Proroga Y., Pesce A., Giuseppina D.M. \& Cringoli G. 2007. Toxoplasma gondii in sheep from the Campania region (Italy). Vet. Parasitol. 149:271-274.

Garcia J.L., Navarro I.T., Ogawa L. \& Oliveira R.C. 1999. Soroprevalência do Toxoplasma gondii em suínos, bovinos, ovinos e eqüinos, e sua correlação com humanos, felinos e caninos, oriundos de propriedades rurais do norte do Paraná, Brasil. Ciência Rural 29:91-97.

Garcia-Vasquez Z., Cruz R.R., Garcia G.D. \& Baungarten O.H. 1993. Seroprevalence of Toxoplasma gondii infection in cattle, swine and goats in four Mexican states. Prev. Vet. Med. 17(1/-2):127-132.

Gondim L.F.P., Barbosa H.V.J., Ribeiro Filho C.H.A. \& Saeki H. 1999. Serological survey of antibodies to Toxoplasma gondii in goats, sheep, cattle and water buffaloes in Bahia State, Brazil. Vet. Parasitol. 82:273-276.

Gorman T., Arancibia J.P., Lorca M., Hird D. \& Alcaino H. 1999. Seroprevalence of Toxoplasma gondii infection in sheep and alpacas (Llama pacos) in Chile. Prev. Vet. Med. 40(3/4):143-149.

Hashemi-Fesharki R. 1996. Seroprevalence of Toxoplasma gondii in cattle, sheep and goats in Iran. Vet. Parasitol. 61:1-3.

Lopes W.D.Z., Santos T.R., Silva R.S., Rossanese W.N., Souza F.A., Rodrigues J.D.A.F., Mendonça R.P., Soares V.E. \& Costa A.J. 2010. Seroprevalence of and risk factors for Toxoplasma gondii in sheep raised in the Jaboticabal microregion, São Paulo State, Brazil. Res. Vet. Sci. 88:104-106.

Mainardi R.S., Stachissini A.V.M., Langoni H., Padovani C.R. \& Modolo J.R. 2000. Soroprevalência de Toxoplasma gondii em rebanhos caprinos no Estado de São Paulo. Revta Bras. Parasitol. Vet. 9(2):97-99.

Masala G., Porcu R., Madau L., Tanda A., Ibba B., Satta G. \& Tola S. 2003. Survey of ovine and caprine toxoplasmosis by IFAT and PCR assays in Sardinia, Italy. Vet. Parasitol. 117:15-21.

Meireles L.R., Galisteo A.J. \& Andrade H.F. 2003. Serological survey of antibodies to Toxoplasma gondii in food animals from São Paulo state, Brazil. Braz. J. Vet. Res. Anim. Sci. 40:267-271.

Millar P.R., Sobreiro L.G., Bonna I.C.F. \& Amendoeira M.R.R. 2008. A importância dos animais de produção na infecção por Toxoplasma gondii no Brasil. Semina 29(3):693-706.

Neto J.O.A., Azevedo S.S., Gennari S.M., Funada M.R., Pena H.F.J., Araújo A.R.C.P., Batista C.S.A, Silva M.L.C.R., Gomes A.A.B., Piatti R.M. \& Alves C.J. 2008. Prevalence and risk factors for anti- Toxoplasma gondii antibodies 
in goats of the Seridó Oriental microregion, Rio Grande do Norte state, Northeast region of Brazil. Vet. Parasitol.156:329-332.

Ogawa L., Navarro I.T., Freire R.L., Oliveira R.C. \& Vidotto O. 2003. Ocorrência de anticorpos anti-Toxoplasma gondii em ovinos da região de Londrina no Estado do Paraná. Semin. 24(1):57-62.

Romanelli P.R., Freire R.L., Vidotto O., Marana E.R.M., Ogawa L. \& De Paula V.S.O. 2007. Prevalence of Neospora caninum and Toxoplasma gondii in sheep and dogs from Guarapuava farms, Paraná state, Brazil. Res. Vet. Sci. 82:202-207.

Samad M.A., Rahman K.B. \& Halder A.K. 1993. Seroprevalence of Toxoplasma gondii in domestic ruminants in Bangladesh. Vet. Parasitol. 47(1):157159.

Sawadogo P., Hafid J., Bellete B., Sung R.T.M., Chakdi M., Flori P., Chait A. \& Dalal A. 2005. Seroprevalence of Toxoplasma gondii in sheep from Marrakech, Morocco. Vet. Parasitol. 130(1/2):89-92.

Sharif M., Gholami S., Ziaei H., Daryani A., Laktarashi B., ZIiapour S.P., Rafiei A. \& Vahedi M. 2007. Seroprevalence of Toxoplasma gondii in cattle, sheep and goats slaughtered for food in Mazandaran province, Iran, during 2005. Vet. J. 174:422-424.

Sharma S., Sandhu K.S., Bai M.S., Kumar H., Verma S. \& Dubey J.P. 2008. Serological survey of antibodies to Toxoplasma gondii in sheep, cattle and buffaloes in Punjab, India. J. Parasitol. 94(5):1174-1175.

Silva A.V., Cunha E.L.P., Meireles L.R., Gottschalks A., Motta R.A. \& Langoni H. 2003. Toxoplasmose em ovinos e caprinos: estudo soroepidemiológico em duas regiões do Estado de Pernambuco, Brasil. Ciência Rural. 33(1):115-119.

Silva A.V. \& Langoni H. 2001. The detection of Toxoplasma gondii by comparing cytology, histopathology, bioassay in mice, and the polymerase chain reaction (PCR). Vet. Parasitol. 97(3):191-198.

Silva J.C.R., Ogassawara S., Adania C.H., Ferreir F., Gennari S.M., Dubey J.P. \& Ferreira J.S. 2002. Seroprevalence of Toxoplasma gondii in captive Neotropical felids from Brazil. Vet. Parasitol. 102:217-224.

Skjerve E., Waldeland H., Nesbakken T. \& Kapperud G. 1998. Risk factors for the presence of antibodies to Toxoplasma gondii in Norwegian slaughter lambs. Prev. Vet. Med. 35:219-227.

Soares H.S., Ahid S.M.M., Bezerra A.C.D.S., Pena H.F.J., Dias R.A. \& Gennari S.M. 2009. Prevalence of anti-Toxoplasma gondii and anti-Neospora caninum antibodies in sheep from Mossoró, Rio Grande do Norte, Brazil. Vet. Parasitol. 160:211-214.

Sobral C.A., Amendoeira M.R.R., Teva A., Patel B.N. \& Klein C.H. 2005. Seroprevalence of infection with Toxoplasma gondii in indigenous Brazilian populations. Am. J. Trop. Med. Hyg. 72(1):37-41.

Van Der Puije W.N.A., Bosompem K.M., Canacoo E.A., Wastling J.M. \& Akanmori B.D. 2000. The prevalence of anti-Toxoplasma gondii antibodies in Ghanaian sheep and goats. Acta Tropica 76(1):21-26.

Zia-Ali N., Fazaeli A., Khoramizade M., Ajeznberg D., Dardé M. \& Valian H.K. 2007. Isolation and molecular characterization of Toxoplasma gondii strains from different hosts in Iran. Parasitol. Res. 101:111-115. 